\title{
Osteology and Radiographic Anatomy of the Pelvis and Hind Limb of Healthy Ring-Tailed Lemurs (Lemur catta)
}

\author{
M. Makungu ${ }^{1 *}$, H. B. Groenewald ${ }^{1}$, W. M. du Plessis ${ }^{2}$, M. Barrows ${ }^{3}$ and K. \\ N. Koeppel ${ }^{4}$ \\ ${ }^{1}$ Department of Anatomy and Physiology, Faculty of Veterinary Science, University of Pretoria, Private \\ bag X04, Onderstepoort 0110, South Africa; \\ ${ }^{2}$ Ross University School of Veterinary Medicine, P. O. Box 334, Basseterre, St. Kitts, West Indies; \\ ${ }^{3}$ Bristol Zoo Gardens, Clifton, Bristol BS8 3HA, UK; \\ ${ }^{4}$ Johannesburg Zoo, Private Bag X13, Parkview, Johannesburg 2122, South Africa
}

\section{${ }^{*}$ Correspondence:}

Tel.: +27 12529 8246;

Fax: +27 125298320

e-mail: modesta_makungu@yahoo.com

\section{Summary}

In family Lemuridae, anatomical variations exist. Considering its conservation status (near threatened) and presence of similarities between strepsirrhines and primitive animals, it was thought to be beneficial to describe the gross osteology and radiographic anatomy of the pelvis and hind limb of ring-tailed lemurs (Lemur catta) as a reference for clinical use and species identification. Radiography was performed in 14 captive adult ring-tailed lemurs. The radiographic findings were correlated with bone specimens from 
two adult animals. Additionally, computed tomography of the hind limbs was performed in one animal. The pelvic bone has a well-developed caudal ventral iliac spine. The patella has a prominent tuberosity on the cranial surface. The first metatarsal bone and digit 1 are markedly stouter than the other metatarsal bones and digits with medial divergence from the rest of the metatarsal bones and digits. Ossicles were seen in the lateral meniscus, inter-phalangeal joint of digit 1 and in the infrapatellar fat pad. Areas of mineral opacity were seen within the external genitalia, which are believed to be the os penis and os clitoris. Variations exist in the normal osteology and radiographic appearance of the pelvis and hind limb of different animal species. The use of only atlases from domestic cats and dogs for interpretative purposes may be misleading.

\section{Introduction}

The ring-tailed lemur (Lemur catta) is primarily distributed in south and south-western Madagascar (Budnitz and Dainis, 1975). It is classified as a near-threatened species by the International Union for Conservation and Nature (IUCN, 2012).

It belongs to order; Primata, suborder; Strepsirrhini, family; Lemuridae and genus; Lemur (Nowak, 1999). Strepsirrhines are characterized by retaining primitive characteristics such as a pointed muzzle, rhinarium, tapetum lucidum, bicornuate uterus, small brain case, epitheliochorial placenta, open eye sockets and prominent scent glands (Jungle, 2003; Ankel-Simons, 2007). Most of them do not look like monkeys, but rather resemble more primitive animals (Ankel-Simons, 2007). Like other primates, strepsirrhines have flat nails in most of the digits, the hind limbs are longer than the forelimbs and they have a high degree of orbital frontality (Ankel-Simons, 2007). 
Anatomical variations have been reported in the family Lemuridae (Jungle, 2003). For example, the bamboo lemur (Hapalemur) differs from other members of the family by having a flat face, shorter muzzle and being more vertical in locomotion (Jungle, 2003).

Due to the presence of similarities between strepsirrhines and primitive animals and anatomical variations within the family Lemuridae, it was thought to be beneficial to describe the gross osteological and radiographic anatomy of the pelvis and hind limb in the healthy ring-tailed lemur as a reference for clinical use, species identification and to provide a radiographic and osteological atlas.

\section{Materials and methods}

\section{Animals}

In total, 14 captive adult healthy ring-tailed lemurs from the Bristol zoo (6), UK, Johannesburg (JHB) zoo (7) and Montecasino Bird Gardens (1), Republic of South Africa (RSA) were radiographed in this study during their annual health examinations. This study was approved by the Animal Use and Care Committee (AUCC) of the University of Pretoria. Of the 14 animals, 10 were females and four were males. The age

of the animals ranged from 1.4 years to 25.7 years (mean: $10.87 \pm 7.6$ years). The minimum weight of the animals was $2.1 \mathrm{~kg}$ and the maximum weight was $3.4 \mathrm{~kg}$ (mean: $2.97 \pm 0.4 \mathrm{~kg})$. There was no significant difference $(P>0.05)$ in the mean age and weight of the animals between males and females. 


\section{Radiography}

Radiography of the pelvis and right hind limb was performed under general anaesthesia and a tabletop technique was used. In eight animals, X-ray machine EVA-HF525 (Comed Medical System Co. Ltd, Kyunggi, Korea) was used at a source to image distance (SID) of $95 \mathrm{~cm}$. Regular speed screen type Fuji medical X-ray films (Fujifilm Corporation, Tokyo, Japan) were used in combination with RAREX green regular intensifying screens (Okamoto manufacturing Co. LTD, Tokyo, Japan). X-ray film processor model CP-345 (ELK Corporation, Tokyo, Japan) was used. All radiographs were obtained with $42 \mathrm{kVp}$ and $\mathrm{mAs}$ ranging from 1.25-2.5 except that in one animal radiographs of the stifle and tarsus were taken using mammography films (UM-MA, Fujifilm Corporation) in combination with mamoray screens (Fujifilm Europe $\mathrm{GmbH}$, Duesseldorf, Germany) at $46 \mathrm{kVp}$ and $5 \mathrm{mAs}$.

In the remaining six animals, X-ray machine Roentgen 703 (GEC Medical Equipment Ltd, Middlesex, England) was used, and images were obtained using a computed radiography (CR) unit (Regius Model 110, Konica Minolta Medical and Graphic, INC., Tokyo, Japan). All radiographs were obtained with $60 \mathrm{kVp}$ and $3 \mathrm{mAs}$ at a SID of $105 \mathrm{~cm}$. Previous radiographs of two animals which were taken before skeletal maturity were retrieved and examined for the location of the physes.

\section{Computed tomography}

Computed tomography of the hind limbs was performed in one animal, which died during the course of the study. The animal was positioned in sternal recumbency with the hind limbs extended caudally. Computed tomography was performed using a Siemens Emotion Duo CT scanner (Siemens Medical Systems, Forchheim, Germany) at 
$130 \mathrm{kV}$ and $30 \mathrm{mAs}$. Transverse slices (2 mm thickness) of the right and left hind limbs from the mid-diaphysis of the right and the left femur to the distal phalanges were obtained at a pitch of 1.35 with a sharp kernel (B80s). Images were viewed using a bone window $(W W=2000, W L=400)$ at a slice thickness of $1.25 \mathrm{~mm}$. The right stifle joint was dissected after CT examination, and radiographs of the lateral meniscus and tissues in the cranial aspect of the joint (joint capsule and infrapatellar fat pad) were obtained.

\section{Gross osteology}

Radiographic findings were correlated with osteology specimens of an adult male ringtailed lemur from the Transvaal museum, RSA and an adult female ring-tailed lemur which died during the course of study.

\section{Bone measurements}

Bone measurements were performed on radiographic images. Maximum length was measured from proximal to distal extremities. Maximum length of long bones, sesamoids and ossicles was measured on the mediolateral $(\mathrm{ML})$ view. For the lateral meniscal ossicle, maximum length was measured on the craniocaudal ( $\mathrm{CrCd})$ view. The $\mathrm{CrCd}$ and $\mathrm{ML}$ diameters were taken on the $\mathrm{ML}$ and $\mathrm{CrCd}$ views, respectively. For the long bones, $\mathrm{CrCd}$ and $\mathrm{ML}$ diameters were taken at the mid-diaphysis. The $\mathrm{ML}$ and $\mathrm{CrCd}$ diameters of sesamoids and ossicles were measured as a maximum diameter perpendicular to the length. The maximum length of the phalanges, tarsal and metatarsal bones was

measured on the dorsoplantar (DPI) view. The transverse diameter of the pelvis was measured from one iliopectineal line to the other on the ventrodorsal (VD) view (O'Brien, 1978). The maximum length was measured on the VD view between two lines drawn 
transversely just caudal and cranial to the margins of the right ischiatic tuberosity and right cranial dorsal iliac spine, respectively. The conjugate diameter was measured from the cranial end of the pelvic symphysis to the sacral promontory on the right lateral $(R L)$ view of the pelvis. For the Os penis and Os clitoris, the length was measured as a maximum distance on either the $M L$ view of the femur, VD or right lateral $(R L)$ views of the pelvis. Measurements were not compensated for magnification.

\section{Statistical analysis}

Data were analysed using Stat View ${ }^{\odot}$ (SAS Institute Inc., Cary, NC, USA) statistical package. The mean, range and standard deviation (SD) were calculated. The unpaired t-test was used to compare the difference in age, weight and pelvic measurements between males and females. Statistical significance was accepted at $P \leq 0.05$. Data are expressed as mean \pm SD.

\section{Results}

Radiographic measurements of bones, sesamoids and ossicles are shown in Tables 13. 
Table 1. Radiographic measurements $(\mathrm{cm})$ not compensated for magnification of the pelvis, os penis, os clitoris and long bones of the right hind limb in healthy captive ring-tailed lemurs

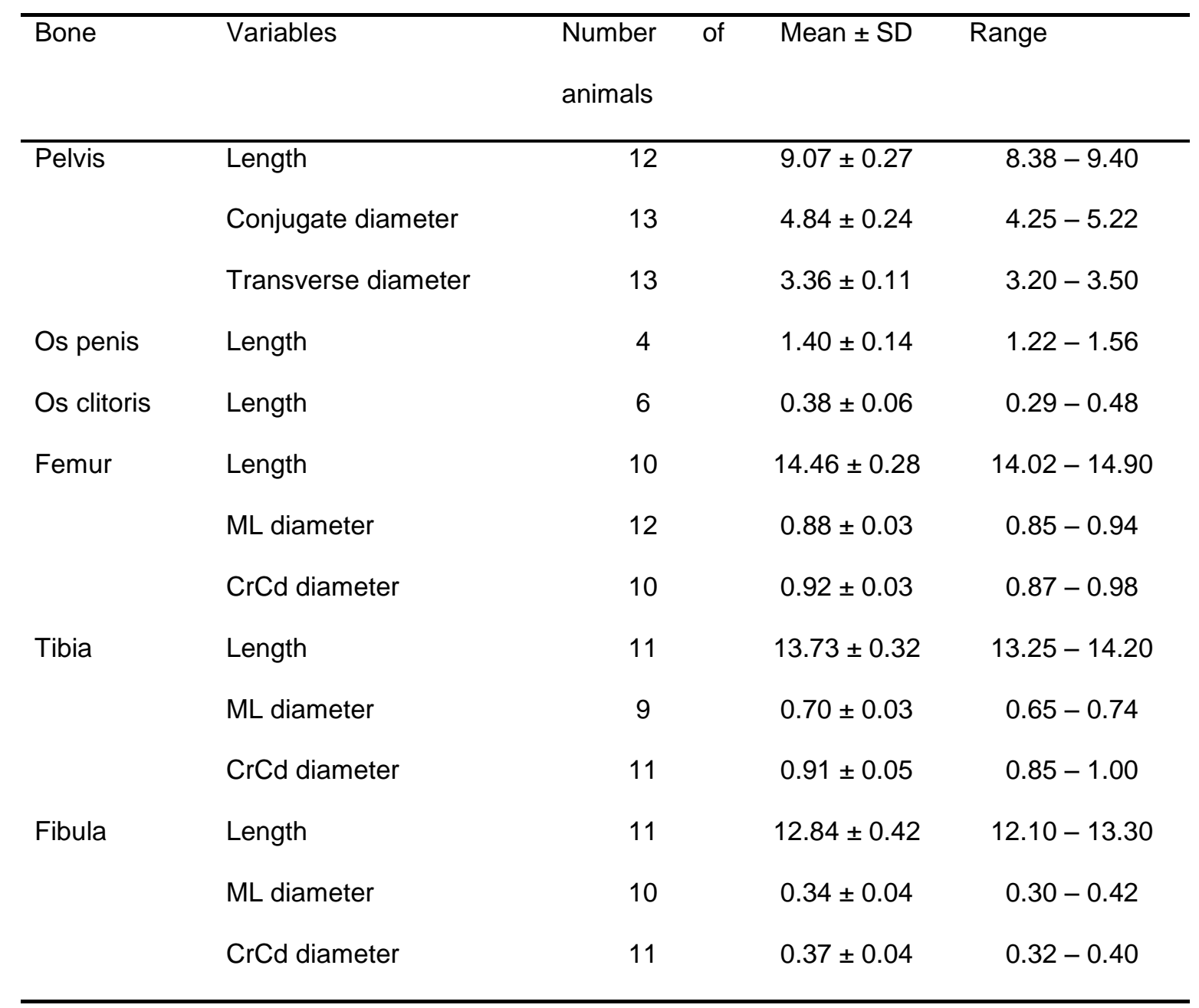


Table 2. Radiographic measurements $(\mathrm{cm})$ not compensated for magnification of sesamoid bones and ossicles of the right hind limb in healthy captive ring-tailed lemurs

\begin{tabular}{|c|c|c|c|c|}
\hline Sesamoid/ossicle & Variables & $\begin{array}{l}\text { Number of } \\
\text { animals }\end{array}$ & Mean \pm SD & Range \\
\hline \multirow[t]{3}{*}{ Patella } & Length & 11 & $1.71 \pm 0.07$ & $1.63-1.80$ \\
\hline & ML diameter & 7 & $0.90 \pm 0.06$ & $0.81-0.98$ \\
\hline & CrCd diameter & 11 & $0.59 \pm 0.05$ & $0.51-0.66$ \\
\hline \multirow[t]{3}{*}{ Lateral fabella } & Length & 11 & $0.34 \pm 0.03$ & $0.30-0.40$ \\
\hline & ML diameter & 8 & $0.47 \pm 0.03$ & $0.42-0.50$ \\
\hline & CrCd diameter & 11 & $0.44 \pm 0.07$ & $0.35-0.55$ \\
\hline \multirow[t]{3}{*}{ Medial fabella } & Length & 11 & $0.47 \pm 0.05$ & $0.41-0.60$ \\
\hline & ML diameter & 11 & $0.38 \pm 0.03$ & $0.33-0.45$ \\
\hline & CrCd diameter & 11 & $0.35 \pm 0.03$ & $0.30-0.40$ \\
\hline \multirow[t]{3}{*}{ Popliteal } & Length & 8 & $0.28 \pm 0.09$ & $0.17-0.40$ \\
\hline & ML diameter & 6 & $0.33 \pm 0.03$ & $0.30-0.37$ \\
\hline & CrCd diameter & 7 & $0.22 \pm 0.03$ & $0.19-0.25$ \\
\hline \multirow[t]{2}{*}{ Meniscal ossicle } & Length & 4 & $0.25 \pm 0.04$ & $0.20-0.30$ \\
\hline & ML diameter & 4 & $0.16 \pm 0.05$ & $0.10-0.20$ \\
\hline \multirow[t]{3}{*}{ Infrapatella fat pad ossicle } & Length & 5 & $0.23 \pm 0.04$ & $0.20-0.30$ \\
\hline & ML diameter & 3 & $0.32 \pm 0.1$ & $0.20-0.40$ \\
\hline & CrCd diameter & 5 & $0.17 \pm 0.03$ & $0.15-0.20$ \\
\hline \multirow[t]{2}{*}{ Interphalangeal ossicle } & Length & 12 & $0.21 \pm 0.04$ & $0.16-0.30$ \\
\hline & ML diameter & 12 & $0.43 \pm 0.05$ & $0.33-0.50$ \\
\hline
\end{tabular}


Table 3. Radiographic measurement $(\mathrm{cm})$ not compensated for magnification of short bones of the right hind limb in healthy captive ring-tailed lemurs

\begin{tabular}{|c|c|c|c|}
\hline Bone & Number of animals & $\begin{array}{l}\text { Length } \\
\text { (Mean } \pm \mathrm{SD})\end{array}$ & Range \\
\hline Calcaneus & 12 & $2.67 \pm 0.13$ & $2.50-2.90$ \\
\hline Talus & 12 & $1.69 \pm 0.05$ & $1.60-1.77$ \\
\hline Central tarsal bone & 12 & $1.19 \pm 0.08$ & $1.08-1.30$ \\
\hline $\mathrm{T} 1$ & 12 & $0.84 \pm 0.09$ & $0.70-0.96$ \\
\hline T2 & 12 & $0.46 \pm 0.04$ & $0.40-0.50$ \\
\hline T3 & 12 & $0.93 \pm 0.11$ & $0.80-1.1800$ \\
\hline T4 & 12 & $0.99 \pm 0.07$ & $0.87-1.10$ \\
\hline MT1 & 12 & $2.83 \pm 0.12$ & $2.70-3.04$ \\
\hline MT2 & 12 & $3.09 \pm 0.15$ & $2.90-3.37$ \\
\hline MT3 & 12 & $3.10 \pm 0.14$ & $2.90-3.32$ \\
\hline MT4 & 12 & $3.13 \pm 0.12$ & $2.90-3.30$ \\
\hline MT5 & 12 & $3.10 \pm 0.16$ & $2.80-3.32$ \\
\hline $\mathrm{P} 1$ of digit 1 & 12 & $1.50 \pm 0.08$ & $1.30-1.63$ \\
\hline $\mathrm{P} 1$ of digit 2 & 11 & $1.82 \pm 0.10$ & $1.62-1.92$ \\
\hline P1 of digit 3 & 10 & $1.97 \pm 0.09$ & $1.76-2.11$ \\
\hline $\mathrm{P} 1$ of digit 4 & 10 & $2.12 \pm 0.11$ & $1.92-2.28$ \\
\hline $\mathrm{P} 1$ of digit 5 & 11 & $1.76 \pm 0.08$ & $1.60-1.91$ \\
\hline P2 of digit 2 & 10 & $1.01 \pm 0.08$ & $0.90-1.10$ \\
\hline P2 of digit 3 & 10 & $1.24 \pm 0.08$ & $1.11-1.32$ \\
\hline P2 of digit 4 & 10 & $1.36 \pm 0.08$ & $1.24-1.46$ \\
\hline P2 of digit 5 & 11 & $1.11 \pm 0.06$ & $1.03-1.20$ \\
\hline P3 of digit 1 & 11 & $0.91 \pm 0.03$ & $0.87-0.97$ \\
\hline P3 of digit 2 & 9 & $0.59 \pm 0.07$ & $0.50-0.70$ \\
\hline P3 of digit 3 & 8 & $0.57 \pm 0.04$ & $0.50-0.60$ \\
\hline P3 of digit 4 & 8 & $0.54 \pm 0.03$ & $0.50-0.60$ \\
\hline P3 of digit 5 & 10 & $0.49 \pm 0.06$ & $0.40-0.59$ \\
\hline
\end{tabular}




\section{Pelvis}

The pelvic bone has a prominent short pelvic symphysis (Figs 1, 2, 3 and 4) and the obturator foramen is equilateral triangular with rounded angles when viewed from dorsally. The iliac crest is almost straight and thin (Figs 1, 2, 3 and 4). The caudal ventral iliac spine is well developed and prominent located just cranial to the cranial acetabular edge (Figs 1, 2, 3 and 4). The gluteal surface is more or less directed laterally (Fig. 2). The ventral border of the ilium bears a flat surface just cranial to the auricular surface sloping from medial to lateral and extending to the cranial ventral iliac spine (Fig. 1). The middle third of the cranial half of the wing is markedly thinner than the dorsal and ventral thirds (Figs 1, 2, and 3). The arcuate line is more prominent (Fig. 1) and divides the sacropelvic surface of the body of the ilium into two almost equal medial and ventromedial surfaces. The medial surface is almost flat, while the ventromedial surface is concave (Fig. 1). The pubis appears L-shaped (Fig. 1), and the ramus and table of the ischium are markedly narrow (Figs 1, 2, 3 and 4). The iliopubic eminence is not prominent (Figs 1 and 2). When viewed from dorsally or ventrally, the body of the ischium converges medially towards the ischiatic tuberosity (Figs 1 and 3). Each ischiatic tuberosity bears a concave depression caudolaterally (Figs 2 and 3), and the ischiatic arc is narrow (Figs 1 and 3 ).

The pelvic measurements were higher in females compared with males although not statistically significant $(P>0.05)$. 


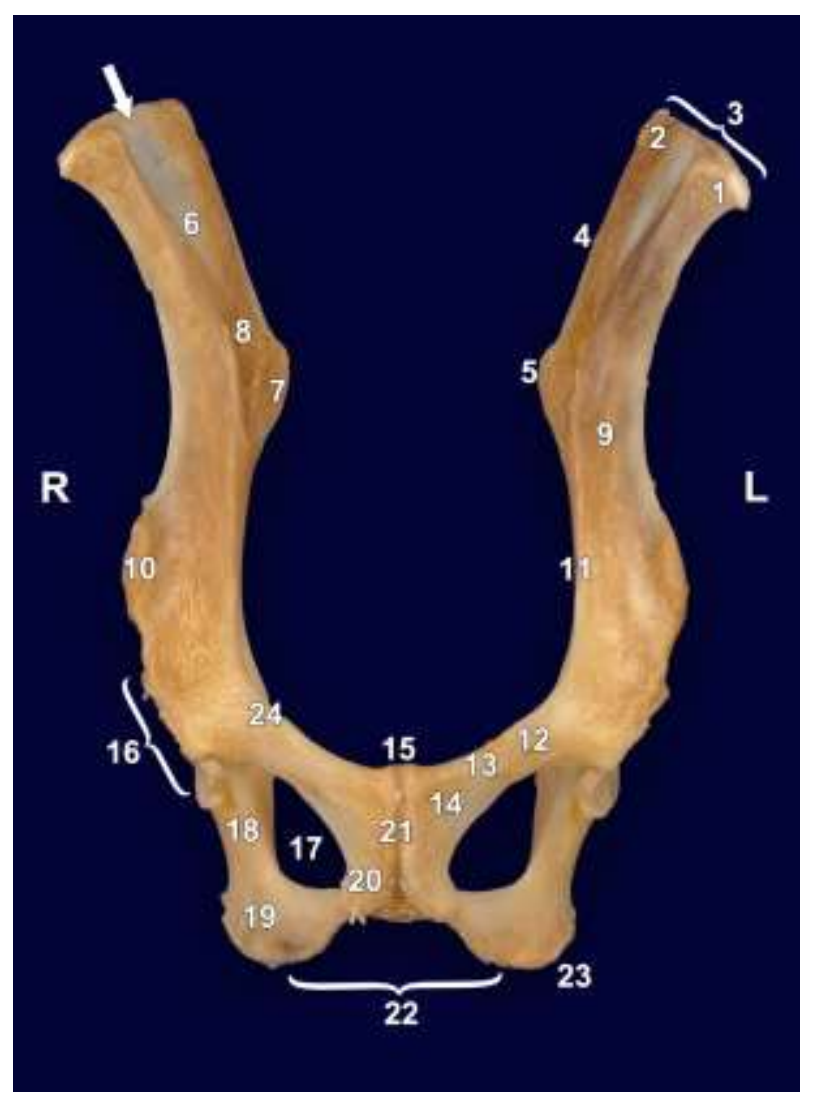

Fig. 1. Ventral view of an anatomical specimen of the pelvic bone of an adult male ring-tailed lemur. Note the presence of the thinner area in the middle third of the cranial half of the wing (arrow). (1) cranial ventral iliac spine, (2) cranial dorsal iliac spine, (3) crest of ilium, (4) wing of ilium, (5) caudal dorsal iliac spine, (6) iliac surface, (7) auricular surface, (8) iliac tuberosity, (9) body of ilium, (10) caudal ventral iliac spine, (11) arcuate line, (12) pubic body, (13) cranial branch of pubis, (14) caudal branch of pubis, (15) pecten of pubic bone (16) acetabulum, (17) obturator foramen, (18) ischiatic body, (19) ischiatic table, (20) ischiatic branch, (21) symphysis pelvis, (22) ischiatic arch, (23) ischiatic tuberosity, (24) iliopubic eminence, $(R)$ right, $(L)$ left. 


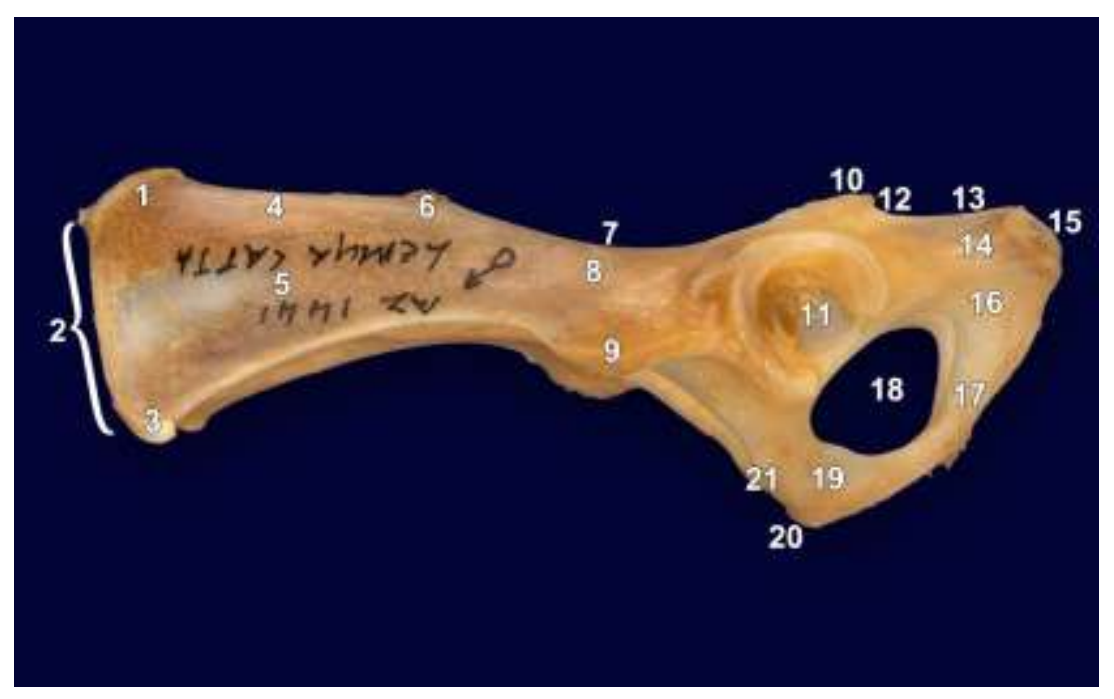

Fig. 2. Left lateral view of an anatomical specimen of the pelvic bone of an adult male ring-tailed lemur. Note the straight appearance of the iliac crest, ventral projection of the caudal ventral iliac spine from the body of ilium, prominent groove for the m. obturatorius internus, absence of psoas minor tubercle and the presence of the thinner area in the middle third of the cranial half of the wing. (1) cranial dorsal iliac spine, (2) crest of ilium, (3) cranial ventral iliac spine, (4) wing of ilium, (5) gluteal surface, (6) caudal dorsal iliac spine, (7) greater ischiatic notch, (8) body of ilium, (9) caudal ventral iliac spine, (10) ischiatic spine, (11) acetabulum, (12) groove for the tendon of the m. obturatorius internus, (13) lesser ischiatic notch, (14) ischiatic body, (15) ischiatic tuberosity, (16) ischiatic table, (17) ischiatic branch, (18) obturator foramen, (19) pubic bone, (20) pecten of pubic bone, (21) iliopubic eminence. 


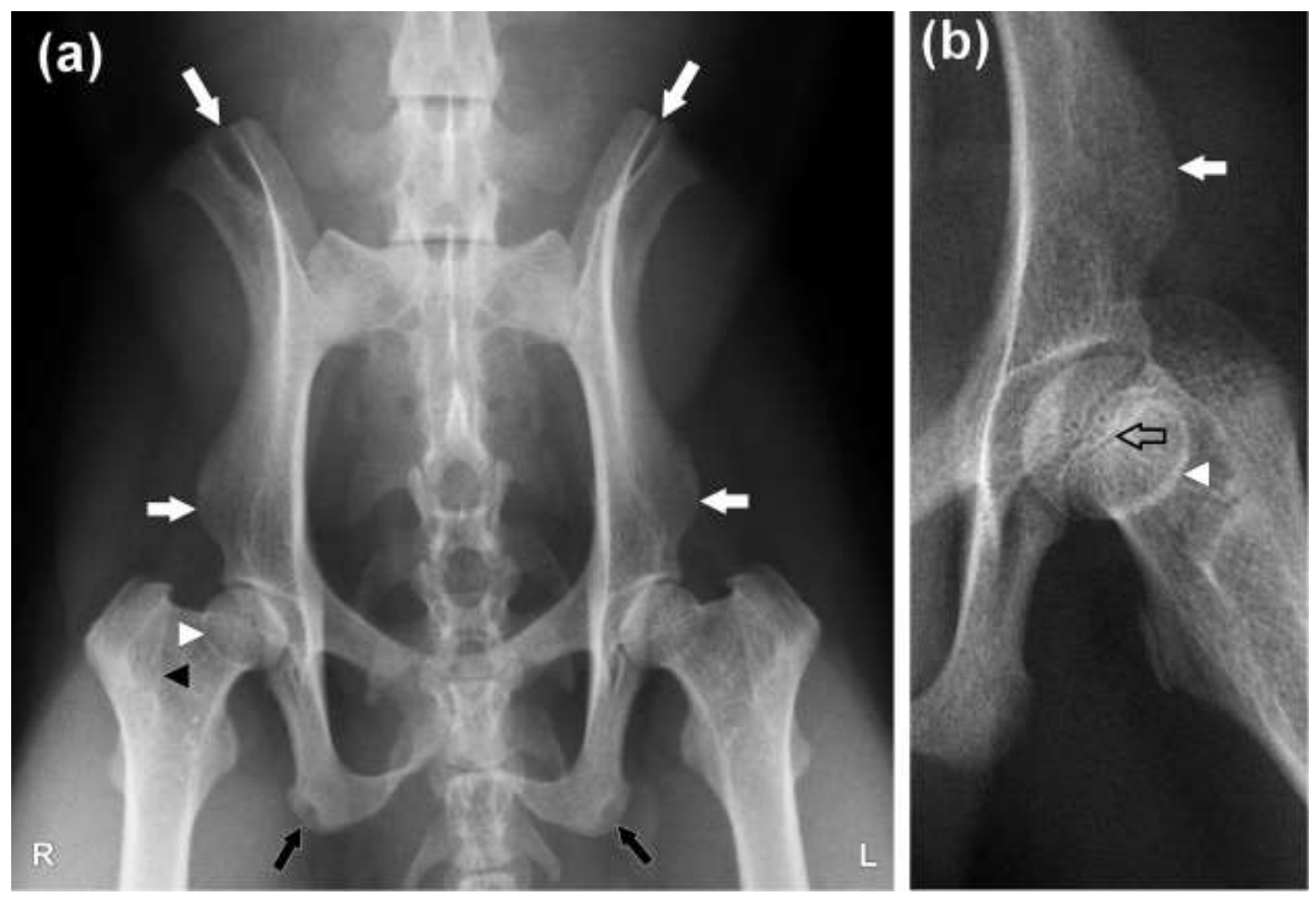

Fig. 3. Ventrodorsal radiographs of the pelvis (a) and left hip joint (b) of 9-year-old female (a) and 9month-old male (b) ring-tailed lemurs. Note the presence of the wedge and ovoid radiolucent areas on each ilial wing (large white arrows) and ischial tuberosity (black arrows), respectively (a). Note also the presence of a prominent third and lesser trochanters and wide, ovoid inter-arcuate spaces between caudal lumbar vertebrae, lumbosacral, sacrococcygeal and cranial coccygeal vertebrae (a). Note the visualisation of the cranial articular margin of the femoral head (white arrow heads), edge of the greater trochanter (black arrow head), caudal ventral iliac spine (small white arrows) and zigzag appearance of the physis of the femoral head epiphysis (open black arrow). (L) left, $(R)$ right. 


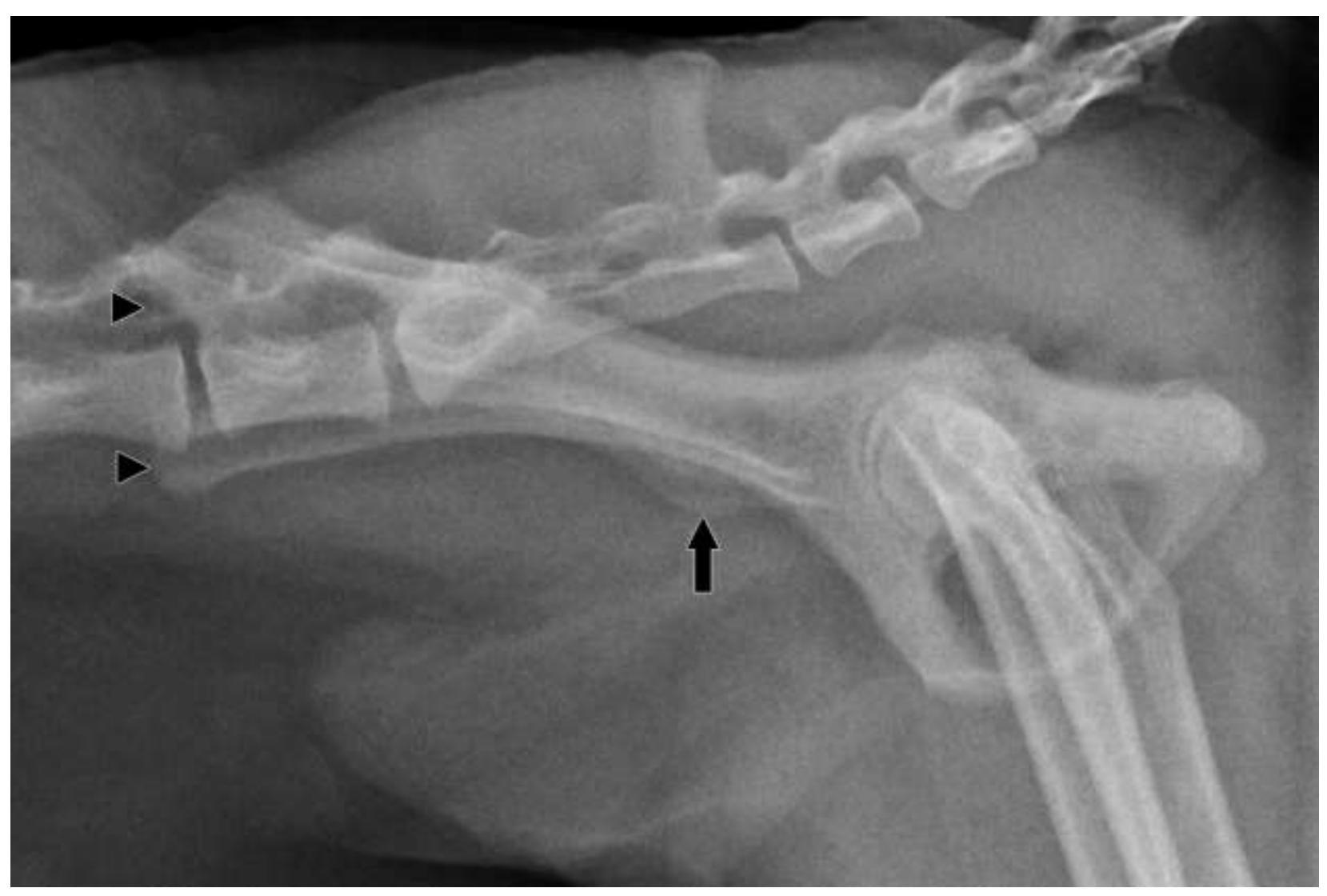

Fig. 4. Right lateral radiograph of the pelvis of a 3.7-year-old female ring-tailed lemur. Crests of the ilia are straight (arrow heads) and caudal ventral iliac spine project ventrally from the body of each ilium (arrow). Note the ovoid superimposed obturator foramina and very short ventral pelvic floor.

\section{Femur}

The femur is generally long and straight (Fig. 5). The cranial and ventral articular margins of the femoral head are more pronounced and elevated from the femoral neck (Fig. 6a) than dorsal and caudal articular margins (Fig. 6b). The caudolaterally located third trochanter is well developed and positioned slightly more distally than the lesser trochanter (Fig. 6a,b). The greater trochanter extends proximal to the femoral head (Fig. 6a,b). The caudomedially located lesser trochanter is prominent and not connected to the greater trochanter by the inter-trochanteric crest (Fig. 6b). The inter-trochanteric 

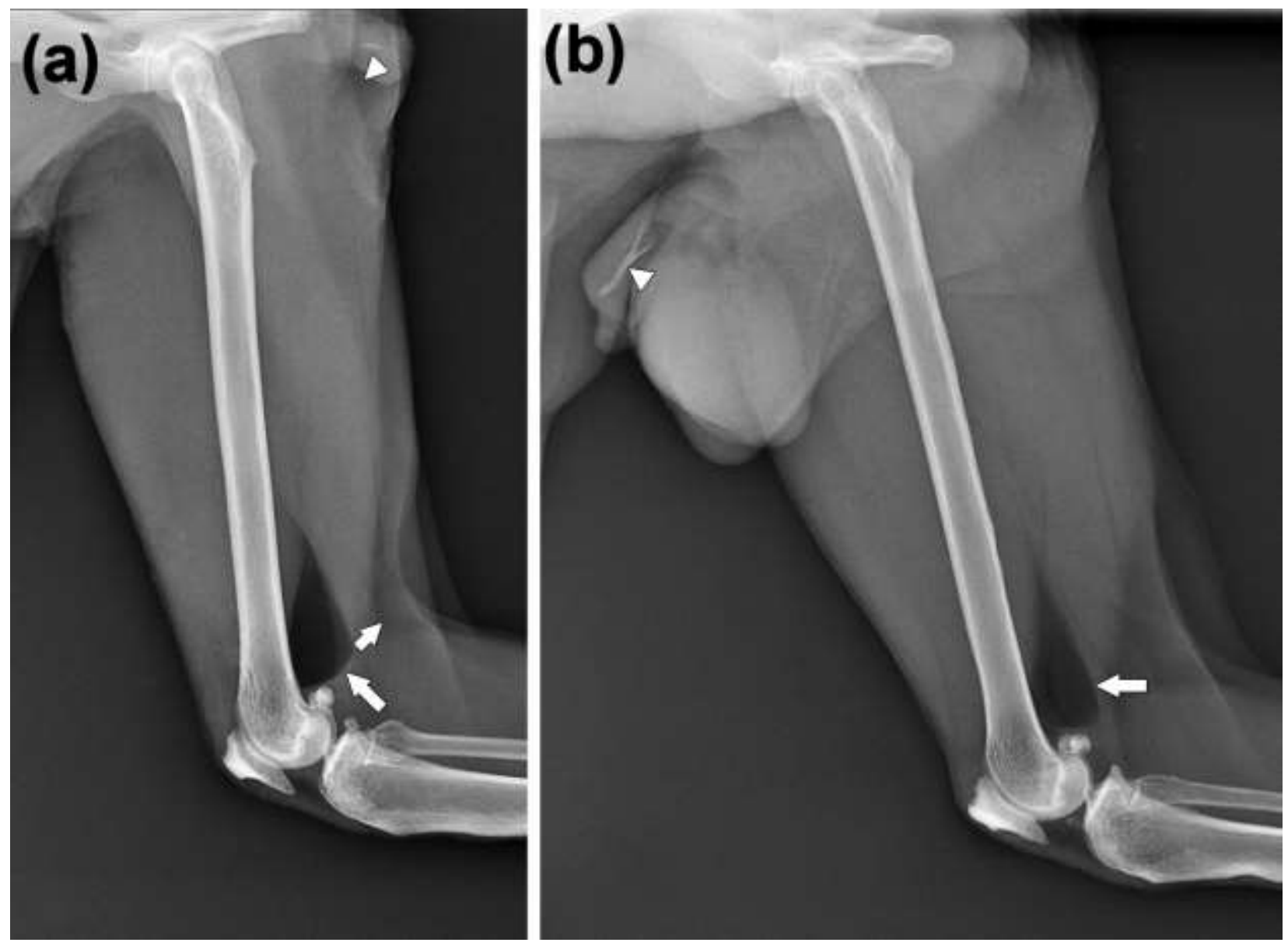

Fig. 5. Mediolateral radiographs of the right femur of a 25.7 (a) and 22.8 (b) year-old female and male ring-tailed lemur, respectively. The femur appears long, straight and slender similar to the domestic cat. A prominent teardrop-shaped (large white arrow) area of fat opacity is seen caudal to the femur just proximal to the lateral and medial fabellae $(a, b)$. Areas of mineral opacity (arrow heads) seen in external genital organs are believed to be os clitoris (a) and os penis (b). The visualization of the popliteal lymph node is indicated by a small white arrow (a). Note the variations in thickness of the cranial and caudal diaphyseal cortices between (a) and (b) which may be related to differences in activity level. 

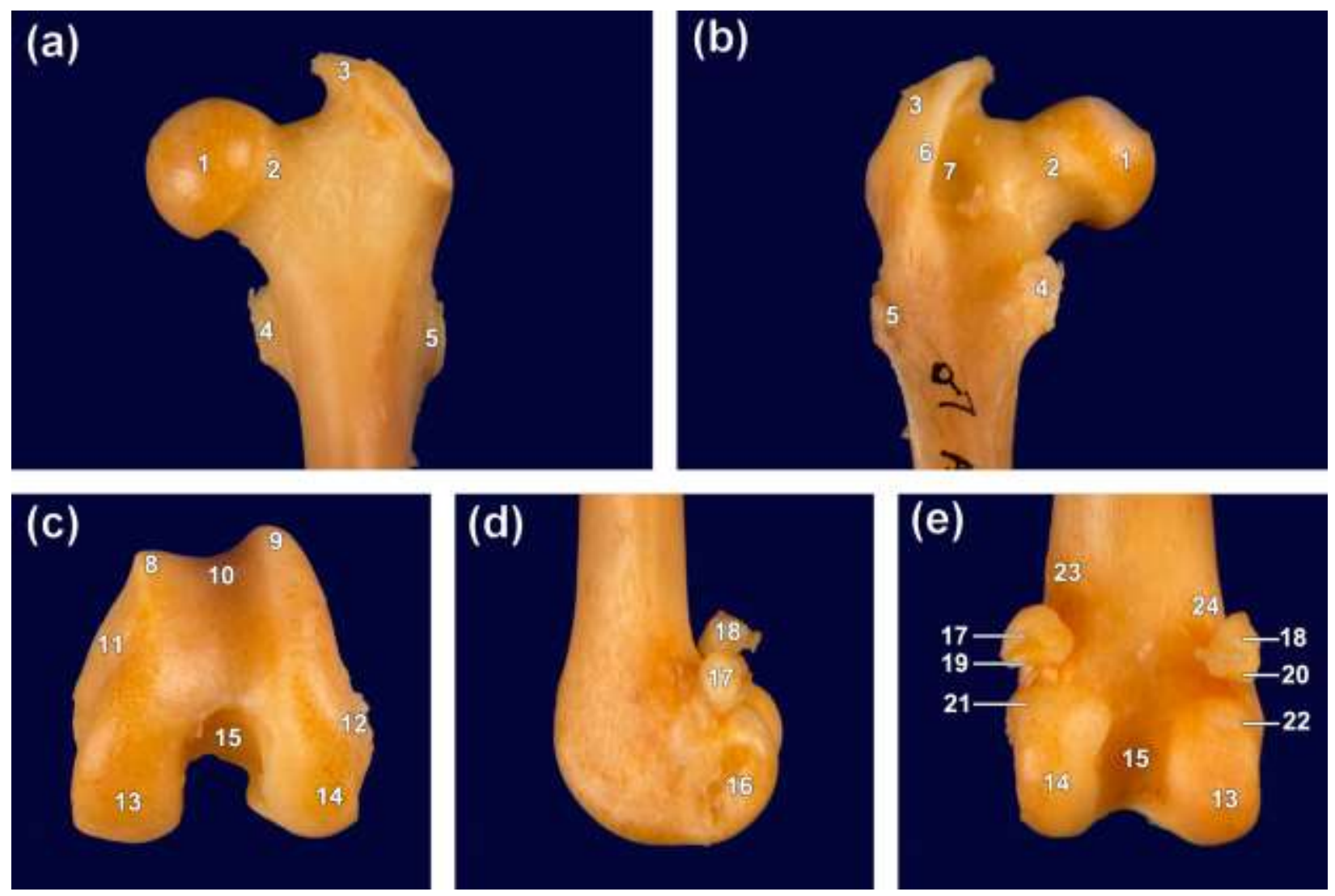

Fig. 6. Cranial (a), caudal (b) and distal (c), lateral (d), caudal (e) views of the proximal and distal anatomical specimen of left femur of an adult male ring-tailed lemur, respectively. (1) head, (2) neck, (3) greater trochanter, (4) lesser trochanter, (5) third trochanter, (6) intertrochanteric crest, (7) trochanteric fossa, (8) medial ridge, (9) lateral ridge, (10) trochlea, (11) medial epicondyle, (12) lateral epicondyle, (13) medial condyle, (14) lateral condyle, (15) intercondylar fossa, (16) popliteal fossa, (17) lateral fabella, (18) medial fabella, (19) articular surface of the lateral fabella, (20) articular surface of the medial fabella, (21) facies articularis sesamoidea lateralis, (22) facies articularis sesamoidea medialis, (23) lateral supracondylar tuberosity, (24) medial supracondylar tuberosity.

crest connects the greater and third trochanters (Fig. 6b). The lateral and medial ridges of the femoral trochlea converge proximally, with the lateral ridge being thicker and more elevated compared with its medial counterpart (Fig. 6c). The popliteal fossa is prominent, while the extensor fossa is absent (Fig. 6d). The lateral supracondylar 
tuberosity is larger and located more proximally than its medial counterpart. Articular facets for the lateral and medial sesamoids of the gastrocnemius muscle (lateral and medial fabellae) are located just distal to the proximal border of the caudal surface of condyles (Fig. 6e). A teardrop-shaped area of fat opacity is seen caudal to the distal femoral metaphysis just proximal to the lateral and medial fabellae (Fig. 5).

\section{Stifle joint}

On the ML view, the patella is similar to that of a feline species with an elongated and pointed apex. There is a tuberosity on the cranial surface of the patella (Fig. 7). The caudal surface of the apex slopes from caudoproximal to craniodistal (Fig. 7). The lateral fabella appears bulbous elongated craniocaudally, whereas the medial fabella appears almost semicircular and rarely pentagonal or triangular (Fig. 7). The popliteal sesamoid is seen as angular or ovoid (Fig. 7). The distal physis of the femur and the proximal physis of the tibia appear similar to those seen in domestic cats and dogs, while the proximal physis of the fibula appears s-shaped (Fig. 7b). On the $\mathrm{CrCd}$ view, the lateral and medial fabellae appear ovoid with the former elongated mediolaterally and the latter proximodistally (Fig. 8). The popliteal sesamoid appears ovoid (Fig. 8). The location of the popliteal sesamoid varies; on the CrCd view, it is seen superimposed on the lateral tibial condyle where it is poorly visualized (Figs 8 and 12a). On the ML view, it is mostly seen caudoproximal to the tibial condyles with its distal extremity superimposed on the tibial condyles (Figs 5 and 7a) and rarely just caudal to the inter-condylar eminence (Fig. 7b) or superimposed on the tibial condyles (Fig. 12b).

In four animals with the age range of 7.3 years to 9.3 years (mean: $8.69 \pm 0.9$ years), a lateral meniscal ossicle was seen (Figs 8, 9 and 10a). The meniscal ossicle 

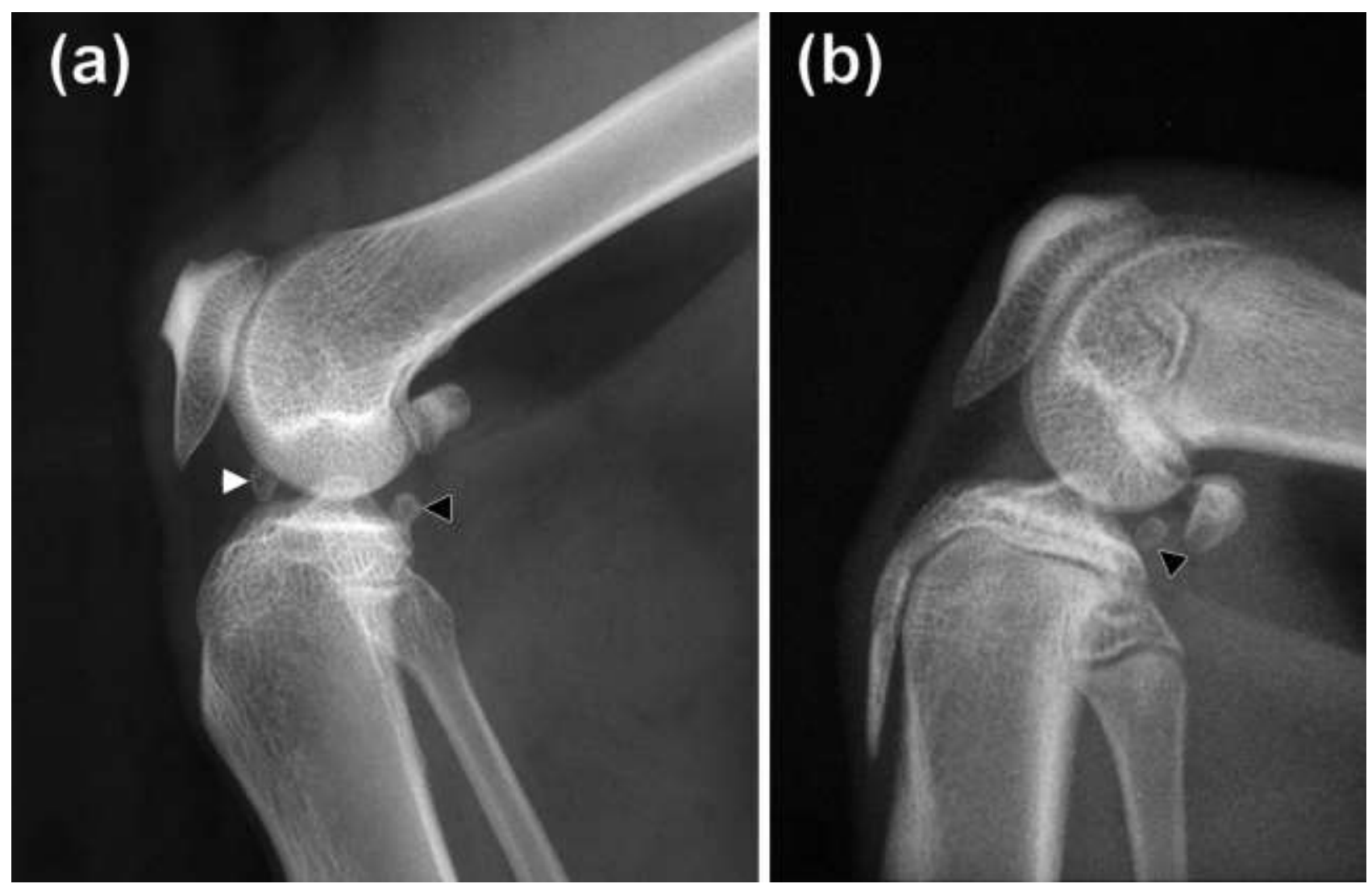

Fig. 7. Mediolateral radiographs of the right stifle joint of 7.3-year-old-female (a) and 9-month-old male (b) ring-tailed lemurs. Note the presence of a tuberosity on the cranial surface of the patella and the sloping of the caudal surface of the apex from proximocaudal to craniodistal $(a, b)$. Note the presence of a popliteal sesamoid (black arrow heads) and a bean-shaped ossicle in the infrapatellar fat pad (white arrow head). Note the bulbous and semicircular superimposed lateral and medial fabellae, respectively. Note also a concave Facies articularis capitis fibulae (a). Note the location further distally of the fibular head (a) which is almost similar to domestic cats. Note also the similar appearance of the distal (zig zag) and proximal physes of the femur and tibia, respectively, as in domestic cats and dogs and the s-shaped proximal fibula physis (b). 

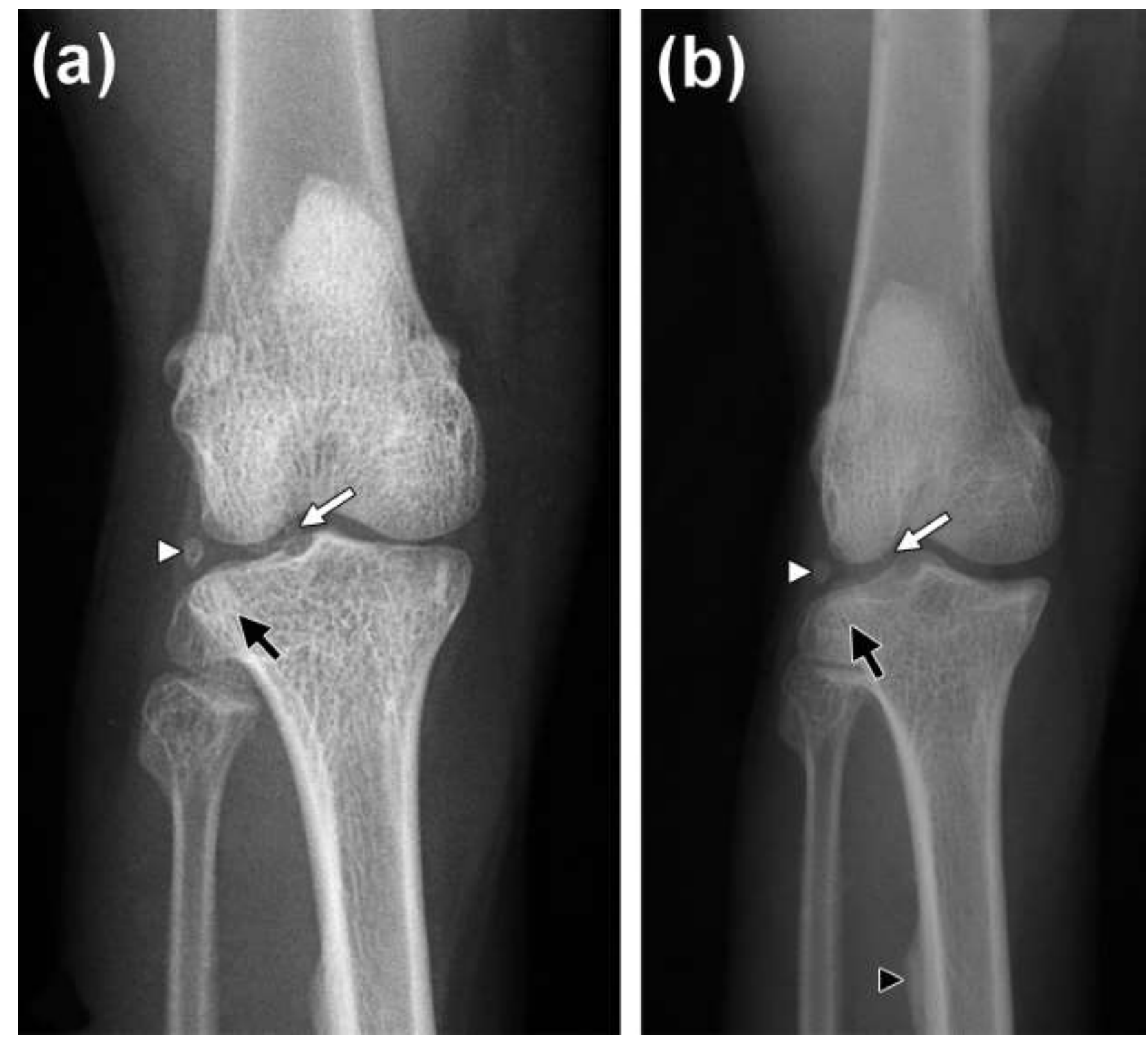

Fig. 8. Craniocaudal radiographs $(a, b)$ of the right stifle joint of a 7.3-year-old-female ring-tailed lemur. (b) Exposure factors have been reduced. An ovoid ossicle in the infrapatellar fat pad (white arrow) is poorly visualized due to its superimposition on the lateral femoral and tibial condyles (a,b). Note the presence of an ovoid lateral meniscal ossicle (white arrow head) laterally within the lateral joint space and the poorly visualized ovoid popliteal sesamoid (black arrow) superimposed on the lateral tibia subchondral bone (a, b). Note also the lateral projection of the area for attachment of the semitendinosus muscle (b) indicated by a black arrow head. The concavity seen on the lateral aspect of the lateral condyle represents the popliteal fossa $(a, b)$. 

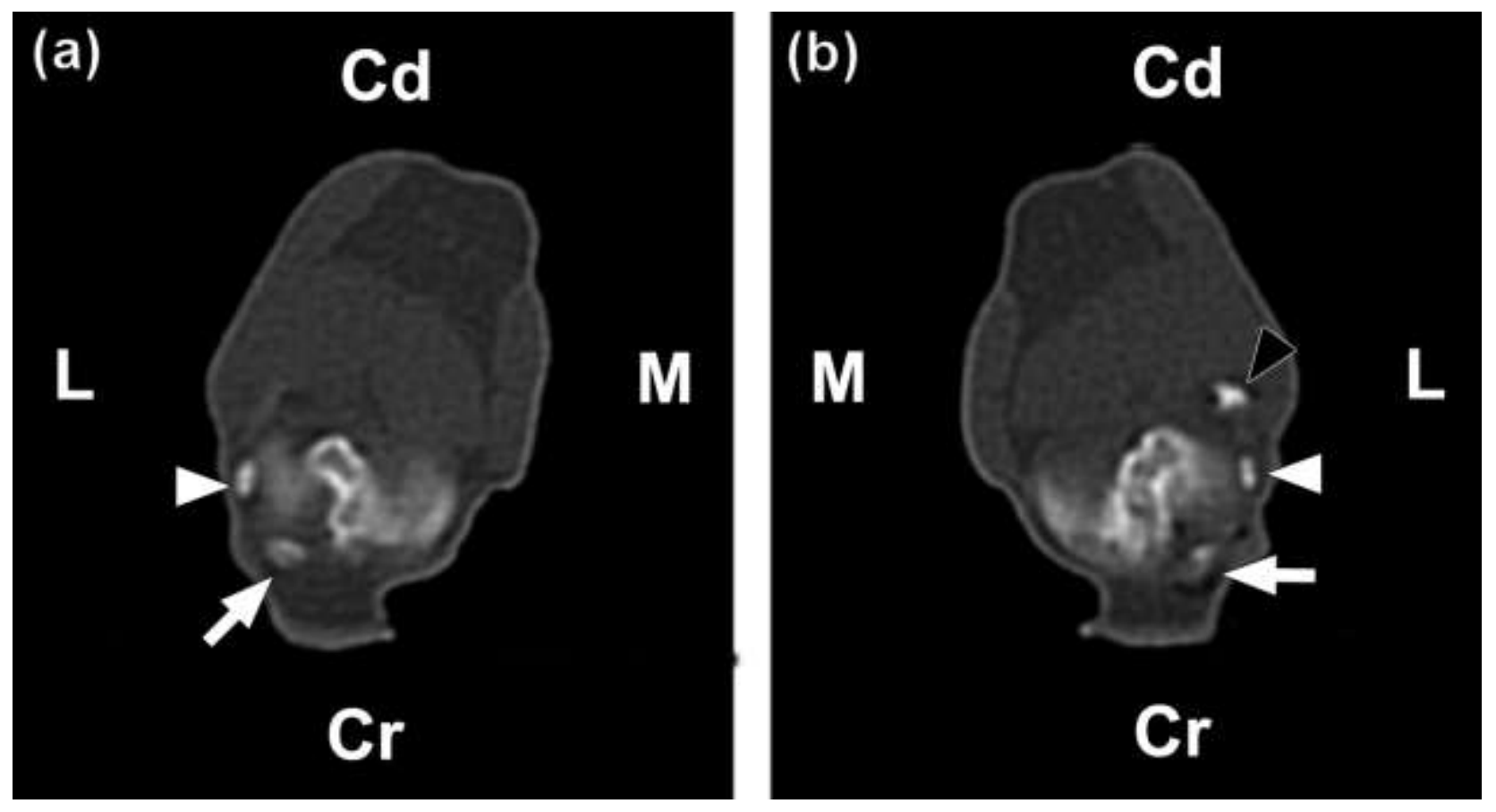

Fig. 9. Transverse CT images of the left (a) and right (b) stifle joints of the same animal in Figs $7 \mathrm{a}$ and 8 at the level of the joint space displayed at a WW 2000, WL 400 using a sharp kernel (B80s). Note the visualisation of the lateral meniscal ossicle (white arrow head), popliteal sesamoid (black arrow head) and an ossicle in the infrapatellar fat pad (white arrow). (Cr) cranial, (Cd) caudal, (M) medial, (L) lateral.

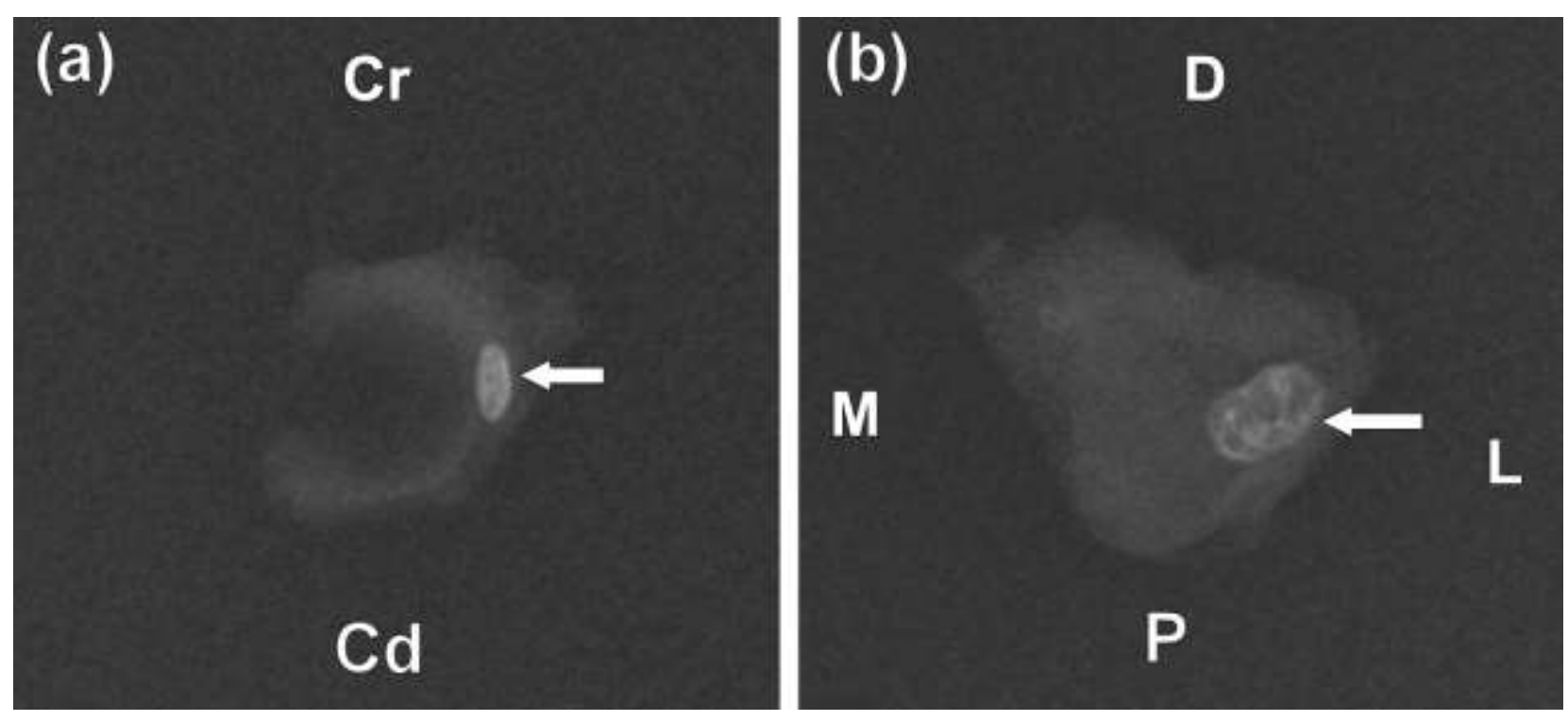

Fig. 10. Proximodistal (a) and $\mathrm{CrCd}$ (b) radiographs of the right lateral meniscus and tissues in the cranial aspect of the right stifle joint (joint capsule and infrapatellar fat pad) of the same animal in Figs $7 a$ and 8 . Note the presence of ovoid ossicles (arrow) with a trabecular pattern surrounded by a sclerotic margin (a, b). Note also the location of the ossicle in the body of the lateral meniscus (a). (Cr) cranial, (Cd) caudal, (D) distal, (P) proximal, (M) medial, (L) lateral. 
appeared ovoid with a sclerotic margin, laterally within the lateral joint space on the CrCd view (Fig. 8). It was not visualized on the ML view (Fig. 7a). Another ossicle located laterally in the infrapatellar fat pad was seen in five animals (Figs 5b, 7a, 8, 9 and $10 \mathrm{~b}$ ) with the age range of 7.3 years to 22.8 years (mean: $11.51 \pm 6.4$ years). On the $M L$ view, the former was mostly seen as an ovoid and rarely bean-shaped bone with a sclerotic margin in the cranial aspect of the joint (Figs 5b and 7a). On the CrCd view, it was poorly visualized due to its superimposition on the lateral femoral and tibial condyles (Fig. 8).

\section{Tibia and fibula}

The proximal extremity of the tibia bears an undivided inter-condylar eminence (Figs 11a and 12a). The Facies articularis fibularis is prominent, ovoid with a convex articular surface (Fig. 11a). The cochlea tibia presents with an almost flat surface without an intermediate ridge (Fig. 11b). When viewed from distally, the Facies articularis malleoli which articulates with the Facies malleolaris medialis of the talus is convex and nearly straight (Fig. 11b). The head of the fibula bears concave Facies articularis capitis fibulae on its proximal surface. The proximal and distal thirds of the body are almost circular in cross-section, while the middle third is semicircular in cross-section. The distal end of the fibula (lateral malleolus) presents with a medial articular facet and a distomedial articular surface (Fig. 11c). The medial articular facet is almost flat and articulates with the fibular notch of the tibia. The distomedial articular surface, Facies articularis malleoli, which articulates with the lateral surface of the talus, (Facies malleolaris lateralis), is slightly concave sloping from medial to lateral (Fig. 11c). 

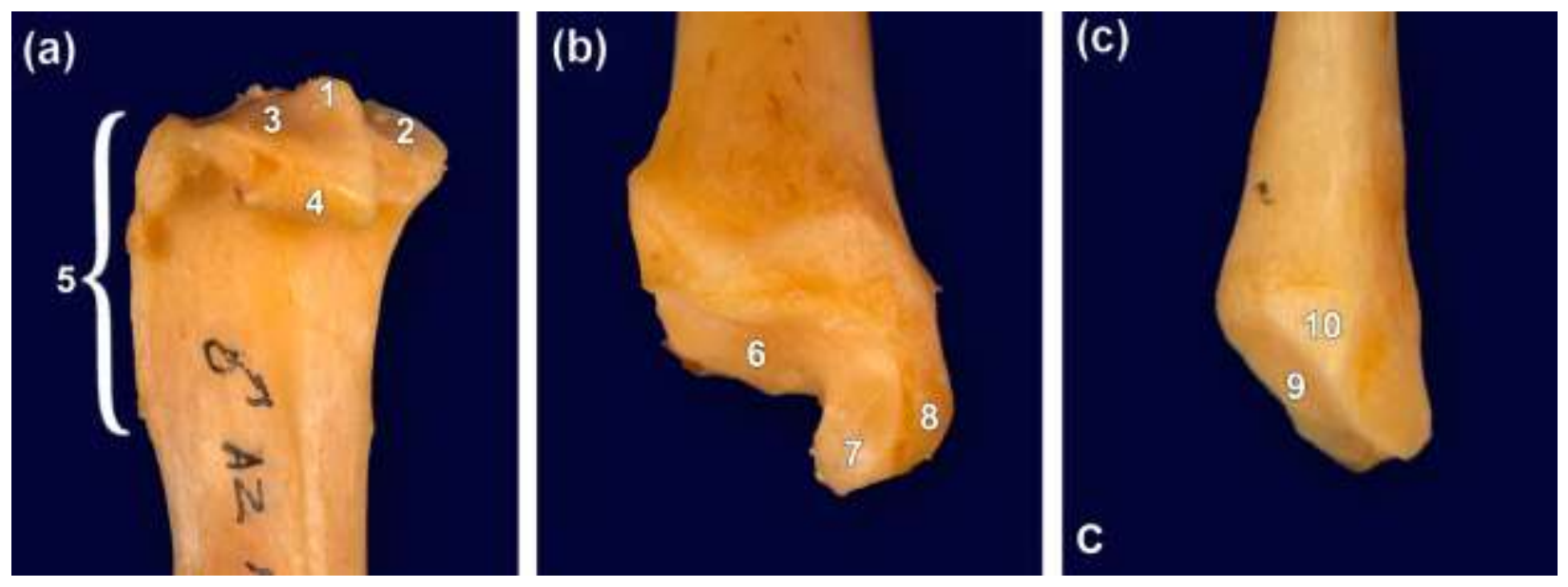

Fig. 11. (a) Caudolateral (b) cranial and (c) craniomedial views of an anatomical specimen of the left proximal tibia, right distal tibia and left distal fibula, respectively, of an adult ring-tailed lemur. (1) intercondylar eminence, (2) medial condyle, (3) lateral condyle, (4) Facies articularis fibularis, (5) tibial tuberosity, (6) cochlea tibia, (7) Facies articularis malleoli of the tibia, (8) medial malleolus, (9) Facies articularis malleoli of the fibula, (10) articular surface for the fibular notch of the tibia.

\section{Tarsus}

The tarsus consists of seven tarsal bones, namely calcaneus, talus, central tarsal bone, fourth tarsal bone (T4), third tarsal bone (T3), second tarsal bone (T2) and first tarsal bone (T1) (Fig. 13). The distal row of the tarsal bones is arranged in such a manner that it is almost semicircular in transverse section (Fig. 13). The trochlea of the talus presents with almost equal-sized medial and lateral ridges separated by a shallow groove. The Facies malleolaris medialis and Facies malleolaris lateralis are concave (Fig. 13). The central tarsal bone is elongated longitudinally and positioned obliquely such that the plantar surface faces plantaromedial. The T3 is elongated longitudinally. The height of T2 is almost half that of T3. The first tarsal bone is roughly L-shaped with the distal half of the bone being elongated in a dorsoplantar direction and almost cylindrical in shape (Fig. 13). 


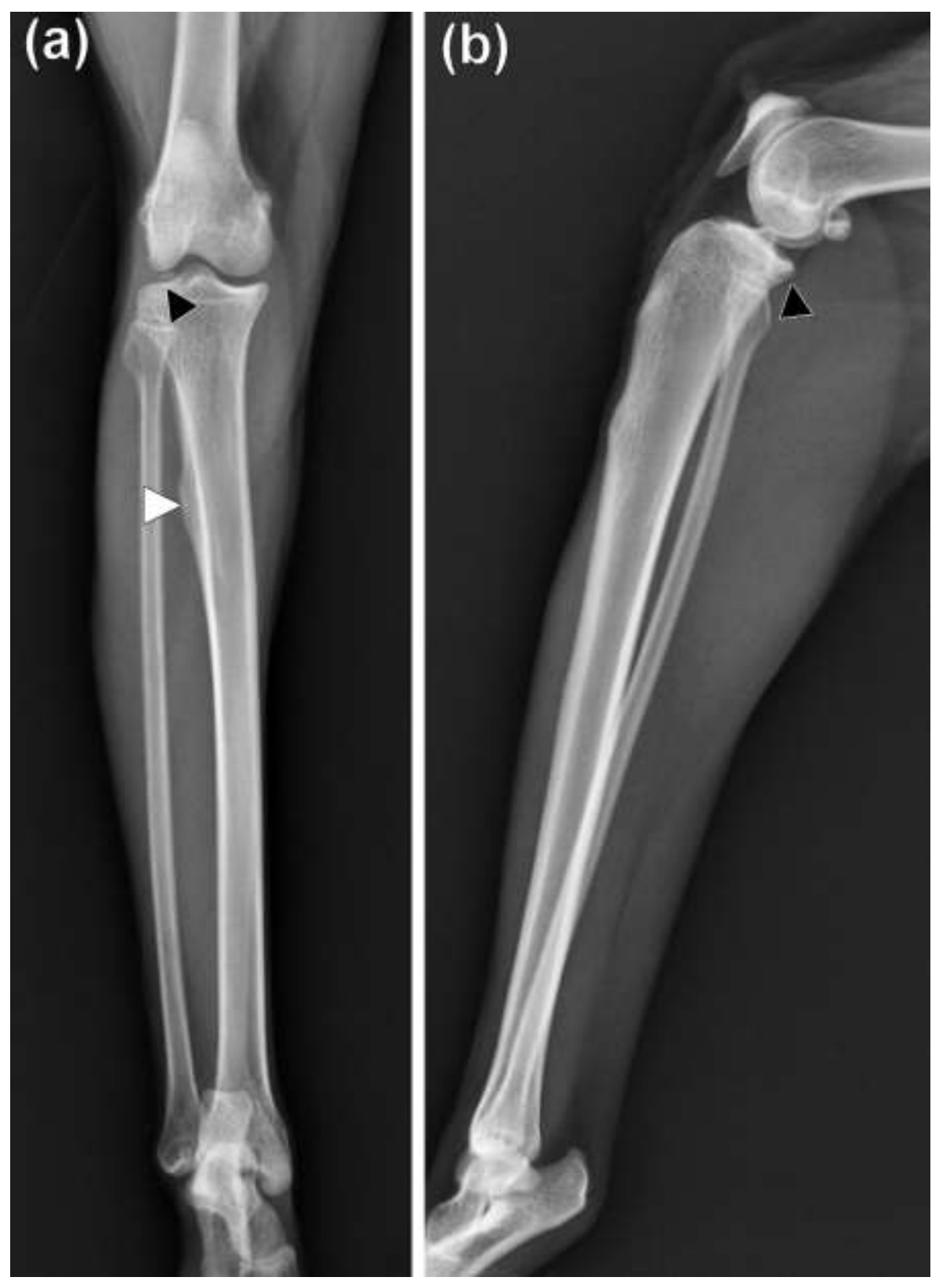

Fig. 12. Craniocaudal (a) and ML (b) radiographs of the right tibia and fibula of 4.8-year-old male and 3.7year-old-female ring-tailed lemurs, respectively. Note the straight appearance of the bones and wide interosseous space which is almost similar to domestic cats $(a, b)$. The lateral projection of the area for attachment of the semitendinosus muscle (white arrow head) is different from domestic cats and dogs (a). The tibial tuberosity is not prominent similar to that of domestic cats (b). Note also the location of the popliteal sesamoid (black arrow head) in the area of the lateral joint space (a) and its superimposition on caudoproximal aspect of tibia condyles (b). Note the uniform thickness of the fibular diaphysis $(a, b)$ 

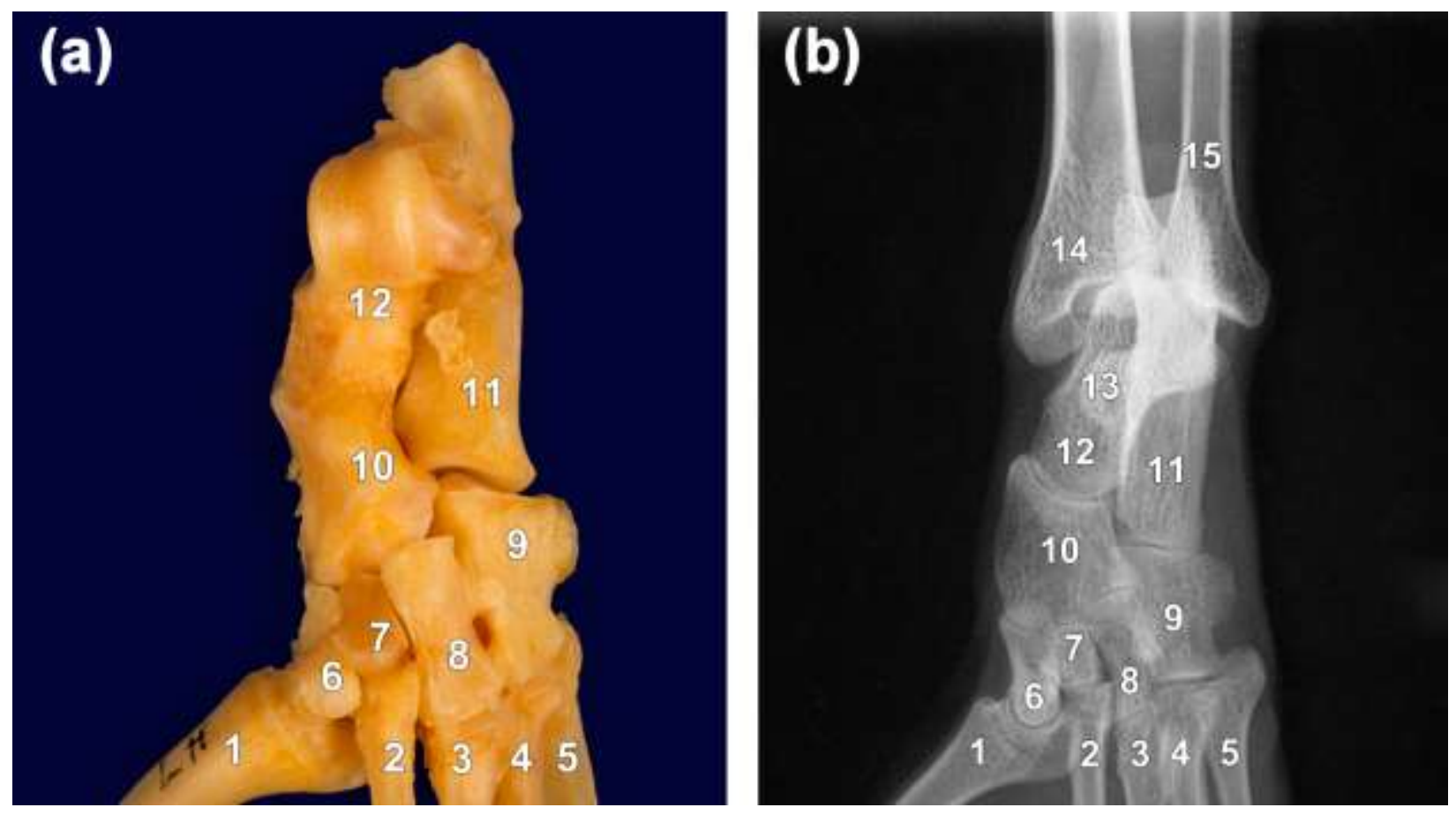

Fig. 13. Dorsal view of an anatomical specimen of the left tarsus of an adult ring-tailed lemur (a). Dorsoplantar radiograph of the right tarsus of a 7.3-year-old female ring-tailed lemur (b). The tarsocrural joint appears flat and Facies articularis malleoli of fibula slopes from medial to lateral (b). Note also the appearance of the tarsocrural joint (b) which is very similar to domestic cats. Note the proximodistal elongation of the central tarsal bone (a,b). (1) MT1, (2) MT2, (3) MT3, (4) MT4, (5) MT5, (6) T1, (7) T2, (8) T3, (9) T4, (10) central tarsal bone, (11) fibular tarsal bone, (12) tibial tarsal bone, (13) Sustentaculum tali superimposed on the tibial tarsal bone, (14) tibia, (15) fibula.

\section{Metatarsus and digits}

There are five metatarsal bones, namely (mediolateral sequence); metatarsal (MT) bones $1-5$ (Fig. 14). The first metatarsal bone is markedly stouter compared to others with a greater medial divergence from the rest of the metatarsal bones. It is positioned in such a way that the dorsal and plantar surfaces face almost medial and lateral, respectively (Fig. 14). There are five digits. Digit 1 has only proximal (P1) and distal (P3) 


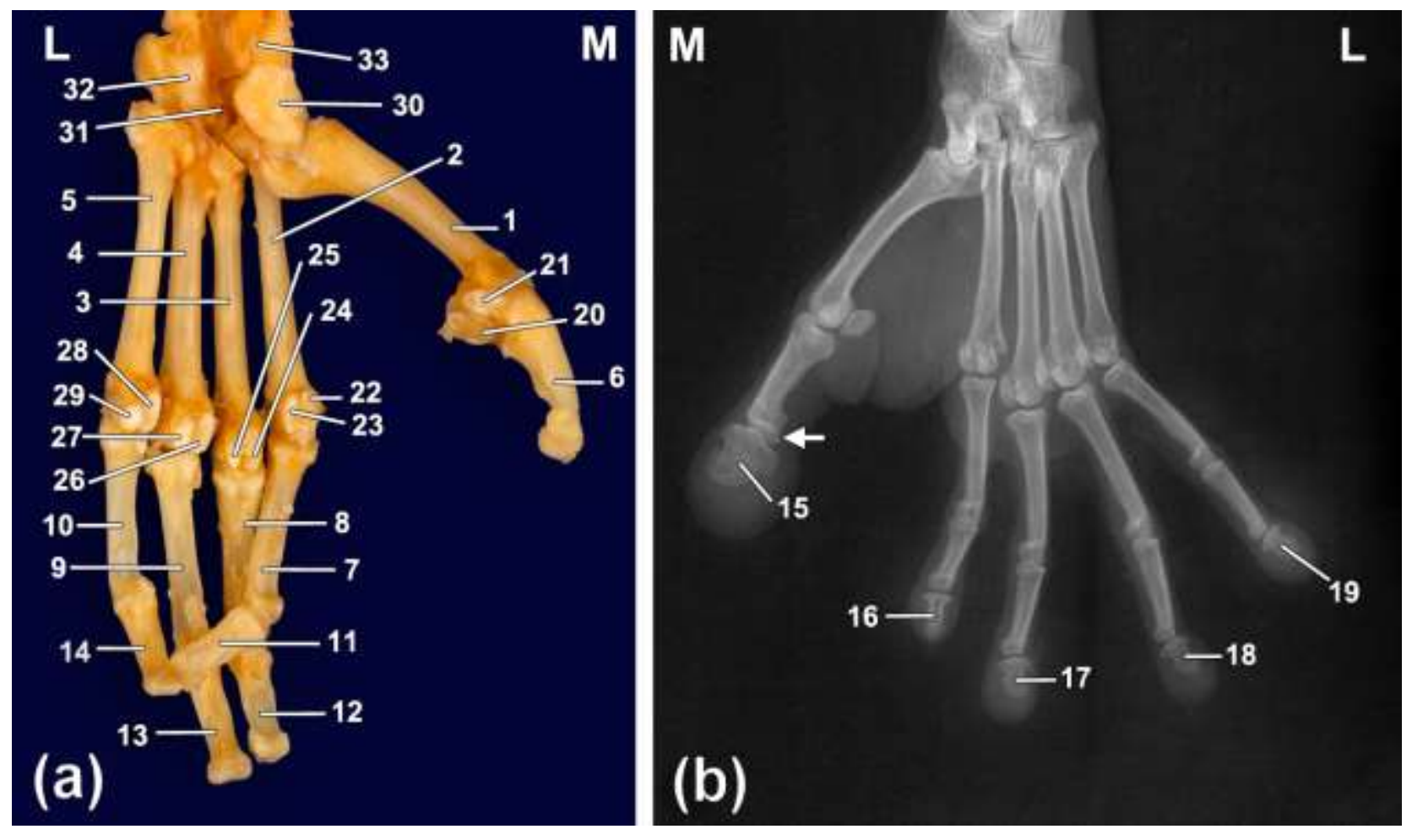

Fig. 14. (a) Plantar view of an anatomical specimen of the left MT and digits of an adult ring-tailed lemur.

(b) Oblique radiograph of the right MT and digits of a 7.3-year-old female ring-tailed lemur obtained from the DPI view of the tarsus. Note the stoutness and medial divergence of the MT1 and digit 1 from the rest of the MT and digits. The shorter abaxial and axial sesamoid bones of digit 1, 4, 5 and digit 2, 3, respectively, compared to their counterparts. An inter-phalangeal ossicle on the plantar aspect of the interphalangeal joint of digit 1 is indicated by an arrow (b). (1) MT1, (2) MT2, (3) MT3, (4) MT4, (5) MT5, (6) P1 of digit 1, (7) P1 of digit 2, (8) P1 of digit 3, (9) P1 of digit 4, (10) P1 of digit 5, (11) P2 of digit 2, (12) P2 of digit 3, (13) P2 of digit 4, (14) P2 of digit 5, (15) P3 of digit 1, (16) P3 of digit 2, (17) P3 of digit 3, (18) P3 of digit 4, (19) P3 of digit 5, (20) axial sesamoid of digit 1, (21) abaxial sesamoid of digit 1, (22) abaxial sesamoid of digit 2, (23) axial sesamoid of digit 2, (24) abaxial sesamoid of digit 3, (25) axial sesamoid of digit 3, (26) axial sesamoid of digit 4, (27) abaxial sesamoid of digit 4, (28) axial sesamoid of digit 5, (29) abaxial sesamoid of digit 5, (30) T1, (31) T3, (32) T4, (33) central tarsal bone.

phalanges, the middle phalanx (P2) is absent. It is shorter and stouter compared to the others (Fig. 14b). 


\section{Metatarsophalangeal and inter-phalangeal joints}

Each metatarsophalangeal joint has paired ovoid (axial and abaxial) plantar sesamoids.

The axial sesamoids of digits 1, 4 and 5 are longer than their counterparts, whereas in digits 2 and 3, the abaxial sesamoids are longer than their counterparts (Fig. 14). An inter-phalangeal ossicle was seen in digit 1 in all animals. The former was seen as either ovoid or crescent shaped on the DPI view of the pes (Fig. 14b).

\section{Other findings}

An area of mineral opacity was seen within the soft tissue of the external genitalia in female and male animals, which are believed to be os clitoris (Fig. 5a) and os penis (Fig. 5b), respectively. Spondylosis deformans was seen in two animals; in one animal between the third sacral (S3) and the first caudal (Cd1) vertebrae and between Cd1 and the second caudal vertebrae (Cd2). In the second animal it was between $\mathrm{Cd} 1$ and $\mathrm{Cd} 2$.

\section{Discussion}

A well developed and prominent caudal ventral iliac spine in ring-tailed lemurs is related to the locomotor adaptation of jumping in this species (Sigmon and Farslow, 1986). The former provides attachment for a well developed and powerful m. rectus femoris, which is an important extensor of the stifle joint during jumping (Sigmon and Farslow, 1986). The caudal ventral iliac spine is also well developed in humans as an adaptation to erect posture whereby it provides an attachment for powerfully developed $\mathrm{m}$. rectus femoris aiding in balancing (Sigmon and Farslow, 1986). M. rectus femoris is not powerfully 
developed in monkeys and apes, and the caudal ventral iliac spine is not prominent as in ring-tailed lemurs and humans (Sigmon and Farslow, 1986).

The markedly thinner area of the middle third of the cranial half of the wing of the ilium observed in this species might be a result of the presence of a stretching ligament, Ligamentum interspinosum (Jouffroy, 1975; Sigmon and Farslow, 1986). The latter increases the surface of the ilial wings without increasing the weight of the bone (Jouffroy, 1975) probably as an adaptation for jumping. The Ligamentum interspinosum attaches to the cranial ventral and caudal ventral iliac spines (Jouffroy, 1975).

An almost laterally directed gluteal surface observed in this species is similar to domestic cats and dogs (Nickel et al., 1986) but different from higher primates (Sigmon and Farslow, 1986). In the latter, the gluteal surface is directed more towards a dorsal direction as an adaptation to a postural habit of sitting or squatting (Sigmon and Farslow, 1986). The latter can be observed in ring-tailed lemurs (Rand, 1935) but not as frequently as in higher primates.

The m. iliopsoas is double in this species (Sigmon and Farslow, 1986) consisting of $\mathrm{m}$. psoas major and $\mathrm{m}$. iliacus, which inserts to the lesser trochanter as in domestic cats and dogs (Nickel et al., 1986). The presence of a concave and wide ventromedial sacropelvic surface of the body of the ilium in this species is different from domestic cats and dogs. In domestic cats and dogs, the ventromedial sacropelvic surface of the body of the ilium is smaller compared to the medial one. The $\mathrm{m}$. iliacus which is being accommodated in the ventromedial sacropelvic surface of the body of the ilium is powerful in this species and functions mainly as a thigh flexor (Sigmon and Farslow, 1986). The strength of this muscle is further supported by the presence of a prominent lesser trochanter. 
The presence of a third trochanter in this species is similar to most strepsirrhines and callitrichids (Sigmon and Farslow, 1986). The former provides insertion for $\mathrm{m}$. gluteus superficialis. A straight femoral shaft observed in this species is a characteristic feature in strepsirrhines and monkeys (Sigmon and Farslow, 1986).

In domestic cats and dogs, the extensor fossa provides the origin for the long digital extensor muscle (Nickel et al., 1986). The latter originates from the cranial border of the lateral tibial condyle, inter-osseous membrane and cranial surface of the head of the fibular in this species (Sigmon and Farslow, 1986), which explains the absence of the extensor fossa on the lateral condyle of the femur in this study. In domestic cats and dogs, the extensor fossa is a useful landmark in distinguishing the lateral and medial condyles of the femur on the ML view of the stifle joint (Comerford, 2006).

The visibility of the cranial articular margin of the femoral head on the VD view of the pelvis and CrCd view of the femur in all animals is the result of an almost perpendicular elevation of the margin from the femoral neck in this species. The visibility of the cranial articular margin of the femoral head should not be misinterpreted as a caudolateral curvilinear osteophyte (Morgan's line) (Mayhew et al., 2002) or physeal scar (Thrall and Robertson, 2011). The cranial articular margin of the femoral head has also been observed in domestic dogs when it is presented en face to the primary beam (Gibbs, 1997).

The presence of a tuberosity on the cranial surface of the patella and the extent of its mineral opacity indicates the high strength of the m. quadriceps femoris. The latter is large and powerful in this species and is related to locomotor adaptation of jumping (Sigmon and Farslow, 1986). The radiographic evidence of both medial and lateral fabellae in all animals is different from humans and domestic cats. In domestic cats, the 
medial fabella may not be visualised radiographically (Arnbjerg and Heje, 1993) whereas in humans, both the lateral and medial fabellae may not be visualised radiographically (Zeng et al., 2012).

The two types of ossicles seen in the stifle joint of the healthy ring-tailed lemur are normal anatomical findings in this species and should be differentiated from intraarticular calcified or ossified lesions and bone fragments from avulsion of the lateral collateral ligament and cranial cruciate ligament in the stifle joint. The presence of the sclerotic rim surrounding the ossicles in our study is similar to the radiographic appearance of the ossicle of the meniscus in humans (Bernstein et al., 1976). The sclerotic rim represents a cortical bone surrounding a trabecular bone (Bernstein et al., 1976) although this was not proven histologically in our study. The ossicle of the meniscus has been reported to occur in species of domestic (Thrall and Robertson, 2011) and non-domestic cats (Ganey et al., 1994; Kirberger et al., 2000; Walker et al., 2002). In the Bengal tiger, the ossicle of the meniscus has been associated with running and jumping whereby the ossicle probably provides a mechanical fulcrum to accommodate the dynamic change in the shape of the meniscus during extension of the stifle, which prevents erosion of the articular surface of the femur and tibia (Ganey et al., 1994). This might also be true for the ring-tailed lemur since their locomotor habit involves springing and branch running (Ankel-Simons, 2007).

The occurrence of the ossicle in the lateral meniscus and its location, observed in this study, is different from domestic cats (Whiting and Pool, 1984) in which the cranial horn of the medial meniscus is involved. The ossicle may involve the medial, lateral or both medial and lateral menisci in primates (Ganey et al., 1994). In man, the intrameniscal ossicles are very unusual, and the medial meniscus is highly involved 
compared to the lateral meniscus (Le Minor, 1990). The cause of variation in the location of the ossicle within the different species cannot be ascertained properly and warrants further research. The presence of the ossicle in the lateral meniscus of the ring-tailed lemur has also been observed previously (Le Minor, 1990). In a study involving the morphology of the lateral meniscus, Le Minor (1990) found that in the genus Lemur where 32 subjects were studied, 13 had one ossicle located at the junction of the body and the cranial horn (usual level), 11 had two ossicles, one located at the usual level and the second in the caudal horn and 8 had no ossicles. However, in this study, only one ossicle was seen located in the body of the lateral meniscus. To the best of our knowledge, the occurrence of an ossicle in the infrapatellar fat pad has not yet been described in healthy domestic and non-domestic animals.

The elongated appearance of the central tarsal bone in a longitudinal direction is related to the locomotor adaptation for jumping in this species. In strepsirrhines, higher values of tarsal length as a percentage of total foot length are found in Galago which has an elongated calcaneus and central tarsal bones which increase the tarsal leverage for jumping (Sigmon and Farslow, 1986). The oblique orientation of the central tarsal bone and the dorsoplantar elongation of the distal half of $\mathrm{T} 1$ is a result of the rotation of MT1 and digit 1. The stoutness and medial divergence of MT1 and digit 1 away from the rest of the digits and metatarsal bones are related to the feet being an efficient grasping tool in non-human primates (Ankel-Simons, 2007).

Variation in the longitudinal length between axial and abaxial metatarsophalangeal plantar sesamoids of the same digit has also been observed in non-domestic cats (Kirberger et al., 2000, 2005). In non-domestic cats, the axial sesamoids were longer than their counter parts (Kirberger et al., 2000, 2005). 
In the human, the location of the inter-phalangeal ossicle directly plantar to the inter-phalangeal joint of digit 1 is associated with the development of anatomical, biomechanical and clinical pathologies (Roukis and Hurless, 1996). They are usually single and bilateral (Roukis and Hurless, 1996) although the presence of double ossicles has also been reported (Davies et al., 2003; Suwannahoy et al., 2012). In humans, they can be located plantarmedial, plantarlateral or plantar to the inter-phalangeal joint of the hallux and their shape varies from spherical, oval, elliptical, rectangular or triangular (Roukins and Hurless, 1996). Its frequency in human varies greatly where it can be as high as $91 \%$ and as low as 0\% (Masaki, 1984; Roukis and Hurless, 1996; Msamati and Igbigbi, 2001; Dharap et al., 2007). The presence of the ossicle in all healthy animals in this study suggests that the ossicle is a normal anatomical finding in this species.

It was difficult in this study to obtain a true DPI view of the metatarsals and digits as a result of the curved arrangement in a transverse direction of the distal row of the tarsal bones and rotation and abduction of digit 1 and $\mathrm{MT} 1$ from the rest of the digits and metatarsal bones. Further, the bone measurements obtained in this study will be slightly higher than the actual values as a result of the effect of magnification (Berry and Thrall, 2007). Spondylosis deformans which has been observed at the sacrococcygeal and between the cranial coccygeal vertebrae in this species is most likely related to more strain exerted in this area as a result of the standing position of the tail during jumping, running and walking.

Although the pelvis and pelvic limb of the ring-tailed lemur shares more anatomical features with domestic cats than with dogs, it also possesses some unique anatomical features. Variations exist in the normal osteology and radiographic anatomy of the pelvis and hind limb of different animal species. Knowledge of the osteological 
and radiographic anatomy of the pelvis and hind limb of individual species is important for species identification and interpretative purposes. The use of only atlases from domestic cats and dogs for interpretative purposes may be misleading.

\section{Acknowledgements}

The authors would like to thank the Organization for Women in Science for the Developing World (OWSDW), Swedish International Development Cooperation Agency (SIDA), University of Pretoria, Johannesburg (JHB) and Bristol Zoos for supporting this study. Dr. Shaw Badenhorst and the Transvaal museum for supplying the bone specimens. Dr. Brett Gardner, Dr. Kathryn Perrin, Dr. Cheekin Lim, Ms. Fania Mohlala, sisters and animal handlers of Ondersterpoort Academic Hospital, Bristol and JHB Zoos for their assistance during CT and radiographic examinations. Mrs. Charmaine Vermeulen and Mrs. Wilma Olivier of University of Pretoria for their assistance in preparation of figures and administrative work, respectively.

\section{References}

Ankel-Simons, F., 2007: Primate Anatomy: An Introduction. Boston: Academic Press.

Arnbjerg, J., and N. I. Heje, 1993: Fabellae and popliteal sesamoid bones in cats. J. Small. Anim. Pract. 34, 95-98.

Bernstein, R. M., H. E. Olsson, R. M. Spitzer, K. E. Robinson, and M. W. Korn, 1976: Ossicle of the Meniscus. Am. J. Roentgenol. 127, 785-788. 
Berry, C. R., and D. E. Thrall, 2007: Introduction to radiographic interpretation. In: Textbook of Veterinary Diagnostic Radiology (D. E. Thrall, ed.). Missouri: Saunders Elsevier. pp. 78-92.

Budnitz, N., and K. Dainis, 1975: Lemur catta: Ecology and behaviour. In: Lemur Biology (I. Tattersall and R. W. Sussman, eds). New York: Plenum Press. pp. 219-235.

Comerford, E. J., 2006: The stifle joint. In: BSAVA Manual of Canine and Feline Musculoskeletal Imaging (F. J. Barr and R. M. Kirberger, eds). Gloucester: BSAVA. pp. $135-149$.

Davies, M. B., K. Abdlslam, and R. J. Gibson, 2003: Interphalangeal sesamoid bones of the great toe: An anatomic variant demanding careful scrutiny of radiographs. Clin. Anat. 16, 520-521.

Dharap, A. S., H. Al-Hashimi, S. Kassab, and M. F. Abu-Hijleh, 2007: Incidence and ossification of sesamoid bones in the hands and feet: A radiographic study in an Arab population. Clin. Anat. 20, 416-423.

Ganey, T. M., J. A. Ogden, N. Abou-Madi, B. Colville, J. M. Zdyziarski, and J. H. Olsen, 1994: Meniscal ossification II. The normal pattern in the tiger knee. Skeletal. Radiol. 23, 173-179.

Gibbs, C., 1997: The BVA/KC scoring scheme for control of hip dysplasia: interpretation of criteria. Vet. Rec. 141, 275-284.

IUCN, 2012: IUCN Red List of Threatened Species. Version 2012.1. Available at: http://www.iucnredlist.org, accessed on 12 September 2012.

Jouffroy, F. K., 1975: Osteology and Myology of the Lemuriform Postcranial Skeleton. In: Lemur Biology (I. Tattersall and R. W. Sussman, eds). New York: Plenum Press. pp. 149-192. 
Jungle, R. E., 2003: Prosimians. In: Zoo and Wild Animal Medicine (M. E. Fowler and R. E. Miller, eds). Missouri: Saunders. pp. 334-346.

Kirberger, R. M., W. M. du Plessis, and P. H. Turner, 2005: Radiologic anatomy of the normal appendicular skeleton of the lion (Panthera leo). Part 2: Pelvic limb. J. Zoo. Wildl. Med. 36, 29-35.

Kirberger, R. M., H. B. Groenewald, and W. M. Wagner, 2000: A radiological study of the sesamoid bones and Os meniscus of the cheetah (Actinonyx jubatus). Vet. Comp. Orthopaed. 13, 172-177.

Le Minor, J. M., 1990: Comparative morphology of the lateral meniscus of the knee in primates. J. Anat. 170, 161-171.

Masaki, T., 1984: An anatomical study of the interphalangeal sesamoid bone of the hallux. Nihon. Seikeigeka. Gakkai. Zasshi. 58, 419--27.

Mayhew, P. D., P. J. McKelvie, D. N. Biery, F. S. Shofer, and G. K. Smith, 2002: Evaluation of a radiographic caudolateral curvilinear osteophyte on the femoral neck and its relationship to degenerative joint disease and distraction index in dogs. J. Am. Vet. Med. Assoc. 220, 472-476.

Msamati, B. C., and P. S. Igbigbi, 2001: Radiographic appearance of sesamoid bones in the hands and feet of Malawian subjects. Clin. Anat. 14, 248-253.

Nickel, R., A. Schummer, E. Seiferle, J. Frewein, H. Wilkens, and K. H. Wille, 1986: The Anatomy of the Domestic Animals Vol. 1. Berlin: Springer-Verlag.

Nowak, R. M., 1999: Order Primate. In: Walker's Mammals of the World (R. M. Nowak, ed.). Baltimore: The Johns Hopkins University Press. pp. 490-631. 
O'Brien, T., 1978: Normal radiographic anatomy of the abdomen. In: Radiographic Diagnosis of Abdominal Disorders in the Dog and Cat (T. O' Brien, ed.). Philadelphia: W. B. Saunders Company. pp. 9-47.

Rand, A. L., 1935: On the habits of some Madagascar Mammals. J. Mammal. 16, 89-104.

Roukis, T. S., and J. S. Hurless, 1996: The hallucal interphalangeal sesamoid. J. Foot. Ankle. Surg. 35, 303-308.

Sigmon, B. A., and D. L. Farslow, 1986: The Primate Hind limb. In: Comparative Primate Biology Vol. 1: Systematics, Evolution, and Anatomy (D. R. Swindler and J. Erwin, eds). New York: Alan R. Liss, Inc. pp. 671-718.

Suwannahoy, P., T. Srisuwan, N. Pattamapaspong, and P. Mahakkanukrauh, 2012: Intra-articular ossicle in interphalangeal joint of the great toe and clinical implication. Surg. Radiol. Anat. 34, 39-42.

Thrall, D. E., and I. D. Robertson, 2011: Atlas of Normal Radiographic Anatomy and Anatomic Variants in the Dog and Cat. Missouri: Elsevier Saunders.

Walker, M., D. Phalan, J. Jensen, J. Johnson, M. Drew, V. Samii, G. Henry, and J. McCauley, 2002: Meniscal ossicles in large non-domestic cats. Vet. Radiol. Ultrasound. 43, 249-254.

Whiting, P. G., and R. R. Pool, 1984: Intrameniscal calcification and ossification in the stifle joints of three domestic cats. J. Am. Anim. Hosp. Assoc. 21, 579-584.

Zeng, S., X. Dong, R. Dang, G. Wu, J. Wang, D. Wang, H. Huang, X. Guo, X. Dong, and R. Dang, 2012: Anatomic study of fabella and its surrounding structures in a Chinese population. Surg. Radiol. Anat. 34, 65-75. 
